\title{
Early motor development in metachromatic leucodystrophy
}

\author{
J ZLOTOGORA, H COSTEFF, AND E ELIAN
}

Department of Paediatrics, Hasharon Hospital, Petah-Tiqva, Children's Department, Loewenstein Hospital, Raanana, and Tel Aviv University, Sackler School of Medicine, Israel

SUMMARY Our 6 patients, and a review of 61 others, showed that in most children with late infantile metachromatic leucodystrophy there was a delay in independent walking. This finding has not been mentioned in descriptions of the typical course of the disease and seems to be its earliest clinical manifestation.

Metachromatic leucodystrophy (MLD) is a progressive degenerative brain disease in which hereditary deficiency of the lysosomal enzyme aryl sulphatase $A$ leads to the massive accumulation of sulpholipide (cerebroside sulphate) in the nervous system and other organs. ${ }^{1}$ Three forms of MLD have been described, according to the age of onset: the late infantile (the most common), the juvenile, and the adult type. The course of the late infantile type is classically described as the appearance of first symptoms between ages 12 and 18 months in a previously normal, ambulant child: 'a child who had already learned to walk becomes unsteady and requires support to stand or walk'. ${ }^{1}$

In the last 2 years we have diagnosed 4 new cases of late infantile MLD and have reviewed the progression of the disease in 2 additional affected siblings of one of them. In all 6 children a delay in walking was noted. A review of all reported cases showed that a delay in independent walking is typical of the late infantile type of MLD. This fact had not been stressed, and since this knowledge may help in the early diagnosis of the disease, we think it worthwhile reporting our findings.

\section{Materials and methods}

The diagnosis of MLD in the 4 newly diagnosed children was based on clinical symptoms and absence, or very reduced activity, of leucocyte aryl sulphatase $A$, in addition to an increased level of protein in the cerebrospinal fluid, or a grossly reduced motor nerve conduction velocity. In the family of one child, two siblings had died with a disease that was clinically similar to that of the affected brother. In all cases the aryl sulphatase A activity in leucocytes was examined in the parents, and they were found to be carriers for the disorder.
Our 6 patients and the reported cases of MLD were studied for details of early motor development. The distribution of the age of independent walking in children with MLD was compared with the data of Frankenburg and Dodds ${ }^{2}$ for normal children. Significance of the difference was assessed by the Kolmogorov-Smirnov 1-sample test. ${ }^{3}$

\section{Results}

All our 6 children were able to sit alone by 6 or 7 months and could walk with support before age 1 year. One of them achieved independent walking when 16 months old, another when 18 months old, and the other 4 when 20 months old.

The age of independent walking in our 6 patients and in the other 61 is summarised in the Figure (details are available on request). 18 of the MLD children could walk at or before age 15 months, and another 17 were reported to be normal in their early motor development. 15 walked at 16-25 months, 7 showed delayed walking (but no details were given), and 10 never walked.

This age distribution of independent walking can be compared with the data of Frankenburg and Dodds, ${ }^{2}$ in which $90 \%$ of the normal children achieved walking before age 15 months. The 67 MLD cases showed an extremely significant $(P<0.01)$ delay in walking, compared with normal children.

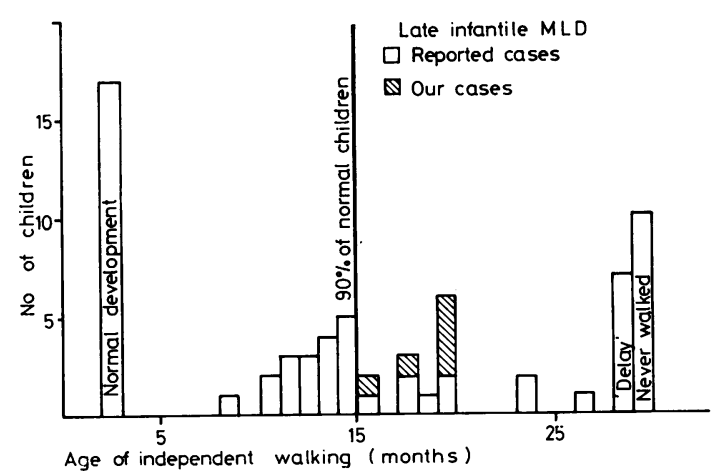

Figure Age at which MLD children began to walk alone compared with normal children. 


\section{Discussion}

On the average, normal children walk alone when 13 months old; $90 \%$ of them achieve independent walking before 15 months. ${ }^{2}$ Children with MLD of late infantile type seem to sit, stand, and begin to walk with support like normal children, but they walk unaided considerably later than normal children. Fewer than $60 \%$ of them walk by 16 months of age, and $15 \%$ never achieve independent walking. This finding seems to have been overlooked in previous reviews of MLD. ${ }^{1}$

MLD is a degenerative disease of the nervous system in which sulpholipide begins to accumulate in various organs during intrauterine development, as has been shown by electron microscopical examination in affected fetuses after therapeutic abortion. ${ }^{14}$ Sulpholipide accumulation in peripheral nerve was demonstrated by biopsy shortly after birth in an affected case, and slowing of the motor nerve conduction velocity was documented at age 8 months in the same child. ${ }^{1}$ These observations support the impression that the first detectable sign in MLD is the early peripheral neuropathy. Therefore, it is not surprising that a delay in independent walking, most probably secondary to the peripheral neuropathy, is the first symptom of the disease in most children, as this study shows. Peripheral nerve motor conduction velocity measured at this early stage should have begun to show a significant reduction.

From the observation of 6 cases, and the review of 61 others, it seems that any description of the typical course of late infantile MLD* should include a significant delay in independent walking. This delay may be the earliest clinical manifestation of the disease.

*Additional data on these 61 cases is available from the authors.

\section{References}

1 Dulaney J T, Moser H W. Sulfatide lipidosis: metachromatic leukodystrophy. In: Stanbury J B, Wyngaarden J B, Frederickson D S, eds. The metabolic basis of inherited disease, fourth edition. New York: McGraw-Hill, 1978: 770.

2 Frankenburg W K, Dodds J B. The Denver development screening test. J Pediatr 1967; 71: 181-91.

3 Siegel S. Non parametric statistics for the behavioral sciences. New York: McGraw-Hill, 1956.

4 Leroy J C, Van Elsen A, Martin J J, et al. Infantile metachromatic leukodystrophy: confirmation of a prenatal diagnosis. $N$ Engl J Med 1973; 288 : 1365-9.

Correspondence to Dr E Elian, Department of Paediatrics, Hasharon Hospital, 7 Keren-Kaymet-le-Israel Street, Petah-Tiqva, Israel.

Received 25 March 1980.

\title{
Rubella and juvenile chronic arthritis
}

\author{
M F SMITH, G B HAYCOCK, AND R GRAHAME \\ Department of Paediatrics, Guy's Hospital, and Arthritis Research Unit, Guy's Hospital Medical School, \\ London
}

SUMMARY A 9-year-old boy with a clinical illness similar to juvenile rheumatoid arthritis was found to have rubella virus in the synovial fluid. There was complete remission of symptoms after 3 months. The role of rubella virus as a possible aetiological agent in juvenile rheumatoid arthritis is discussed.

The systemic form of juvenile chronic arthritis (JCA) presents diagnostic difficulties. Similar clinical illnesses with arthritis have been described in association with coxsackie and adenovirus infections. ${ }^{1}$ Naturally-acquired rubella infection may be complicated by a polyarthritis although this is rare in children; it occurs more often in women. ${ }^{2}$

We describe a 9-year-old boy with a clinical history that suggested systemic onset JCA and in whom rubella virus was isolated from the synovial fluid.

\section{Case report}

A previously healthy 9-year-old white boy was admitted to hospital with a 3-week history of sore throat followed by high fever, muscle pains, and neck 